\title{
Transient unsaturated shaft resistance of a single pile during water flow
}

\author{
Daniel Batista Santos ${ }^{1}$, Moisés Antônio da Costa Lemos ${ }^{1}$, and André Luís Brasil Cavalcante ${ }^{1, *}$ \\ ${ }^{1}$ Department of Civil and Environmental Engineering, University of Brasilia, Zip Code 70910-900, Brazil
}

\begin{abstract}
The pile foundations' design is commonly based on the soil's initial in situ condition during field investigations or the assumption of its saturated condition. However, for some regions in tropical weather, a significant part of the pile shaft remains above the groundwater table (i.e., unsaturated condition) during the structure's lifespan. Only considering a constant moisture condition in the soil (unsaturated or saturated) can overestimate or underestimate the pile design. The soil shear strength governs the shaft resistance of a pile and depends on the soil matric suction, which is significant in the unsaturated zone. In this study, an analytical model is proposed to estimate piles' unsaturated shaft resistance and encourage the use of unsaturated soil mechanics in engineering practice. The mathematical equation involves well-known parameters from unsaturated soil mechanics theory and simulates the pile shaft resistance variation with its length and time, considering a unidimensional infiltration downwards (e.g., during a rainfall event).
\end{abstract}

\section{Introduction}

The verticalization of cities and the demand for larger constructions (e.g., tall buildings, bridges) compels the use of deep foundations (mainly piles) with the accurate subsurface investigation. The soil resistance is underestimated if the structure design criteria (e.g., foundation, slope stability) is based only on a saturated soil mechanics approach. The unsaturated approach, which takes into account the two fluid phases in the porous media, represents the soil behavior more accurately for different moisture conditions ( $\mathrm{Lu}$ and Likos 2004 [1]; Fredlund et al. 2012 [2]). One of the most important state variables for soil stability analysis is the shear strength, which in the unsaturated state its constitutive model includes the soil matric suction state variable (Bishop 1959 [3]; Lu et al. 2010 [4]).

Vanapalli and Taylan (2012) [5] conducted some reduced-scale experiments to investigate the application of unsaturated shear strength models on shaft resistance of a single pile, demonstrating the unsaturated approach applicability on shear strength. Lu et al. (2010) [4] proposed and validated a model of unsaturated shear strength, neglecting the pulling force between soil particles due to the contractile skin (the fourth phase of the soil).

The soil-water retention curve (SWRC) that correlates the soil suction and the soil moisture, defined by Cavalcante and Zornberg (2017) [6], allows analytical transient solutions for Richard's equation, which models the infiltration into unsaturated soil. This model is advantageous because it suits parametric evaluations of the moisture during water infiltration in the soil.

Coupling these main studies, this paper aims to develop an analytical equation to the transient unsaturated shear strength and simulate a single pile's transient shaft resistance during rainfall events. This modeling should provide important insights into the unsaturated soil resistance approach and its use in engineering practice.

\section{Literature review}

\subsection{Shear strength and pile shaft resistance}

An extension of the Mohr-Coulomb failure criterion for unsaturated soil is related to two independent stress state variables: net normal stress $\left(\sigma_{v}-u_{a}\right)$ and matric suction $\left(u_{a}-u_{w}\right)$ (Fredlund et al. 2012 [2]). Bishop (1959) [3] proposed the following equation for the unsaturated shear strength $(\tau)$ envelope:

$$
\tau=c^{\prime}+\left[\left(\sigma_{v}-u_{a}\right)+\chi\left(u_{a}-u_{w}\right)\right] \tan \phi^{\prime}
$$

where $c^{\prime}=$ effective cohesion $\left(\mathrm{ML}^{-1} \mathrm{~T}^{-2}\right) ; \sigma_{v}=$ vertical effective stress $\left(\mathrm{ML}^{-1} \mathrm{~T}^{-2}\right) ; \phi^{\prime}=$ effective internal friction angle; $u_{a}=$ pore-air pressure $\left(\mathrm{ML}^{-1} \mathrm{~T}^{-2}\right) ; u_{w}=$ pore-water pressure $\left(\mathrm{ML}^{-1} \mathrm{~T}^{-2}\right)$; and $\chi=$ soil parameter dependent on the degree of saturation $(S)$ and varies from 1 to 0 .

Lu et al. (2010) [4], with a thermodynamic approach, deduced that $\chi$ equals $S$ when neglecting the capillary contribution to unsaturated shear strength. However, they adopted the variable $S_{e}$ - effective degree of saturation instead of $S$ to nullify the suction contribution towards the residual zone's shear strength. The equation for unsaturated shear strength is then, as shown below:

$$
\tau=c^{\prime}+\left[\left(\sigma_{v}-u_{a}\right)+S_{e}\left(u_{a}-u_{w}\right)\right] \tan \phi^{\prime}
$$

where $S_{e}=\left(S-S^{\prime}\right) /\left(1-S^{\prime}\right)$ and $S^{\prime}=$ residual degree of saturation.

The shear strength on a vertical surface, as the pile

* Corresponding author: abrasil@unb.br 
shaft, can be obtained by applying the coefficient of earth pressure $(K)$ on the effective vertical stress term $\left(\left(\sigma_{v}-u_{a}\right)+S_{e}\left(u_{a}-u_{w}\right)\right)(\mathrm{Lu}$ and Likos 2004 [1]), which allows a continuous transition of the shear strength between the unsaturated and saturated state (when $S_{e}=1$ ).

$$
\tau=c^{\prime}+\beta\left[\left(\sigma_{v}-u_{a}\right)+S_{e}\left(u_{a}-u_{w}\right)\right]
$$

where $\beta=K \tan \phi$ ' (Burland 1973 [7]; Vanapalli and Taylan 2012 [5]).

The drained saturated shaft resistance $\left(u_{a}=0, S_{e}=1\right.$, and $\left.u_{w}=\gamma_{w} z\right)$ is then as follows:

$$
Q_{f}=\int_{0}^{L} P \tau d z=\left[c^{\prime}+\beta\left(\gamma_{\text {sat }}-\gamma_{w}\right) L / 2\right] P L
$$

where $Q_{f}=$ drained shaft resistance $\left(\mathrm{MLT}^{-2}\right)$, considering the failure surface on soil-soil interface adjacent to the pile surface; $L=$ pile length (L); and $P=$ cross-section perimeter $(\mathrm{L}) ; \gamma_{w}=$ water unit weight $\left(\mathrm{ML}^{-2} \mathrm{~T}^{-2}\right)$; and $\gamma_{\text {sat }}=$ saturated soil unit weight $\left(\mathrm{ML}^{-2} \mathrm{~T}^{-2}\right)$. Eq. (4) contemplates a homogeneous soil layer, but it can also handle a variation of those properties $\left(c^{\prime}(z), \beta(z), \gamma_{\text {sat }}(z)\right.$, and $\left.P(z)\right)$ along with depth $(z)$.

\subsection{Soil suction and transient unsaturated flow}

Cavalcante and Zornberg (2017) [6] proposed a model considering one fitting parameter for the soil-water retention curve (SWRC) and a linear function concerning volumetric water content $(\theta)$ for the hydraulic conductivity function. The study solved Richard's equation - which governs the unsaturated flow through porous media by a rigorous approach - analytically for a one-dimensional flow. The SWRC function was deduced as:

$$
\theta(\psi)=\left(\theta_{s}-\theta_{r}\right) \exp (-\delta \psi)+\theta_{r}
$$

where $\delta=$ fitting hydraulic parameter $\left(\mathrm{M}^{-1} \mathrm{LT}^{2}\right) ; \psi=$ absolute value of the total soil suction $\left(\mathrm{ML}^{-1} \mathrm{~T}^{-2}\right) ; \theta_{r}=$ residual volumetric water content $\left(\mathrm{L}^{3} \mathrm{~L}^{-3}\right)$; and $\theta_{s}=$ saturated volumetric water content $\left(\mathrm{L}^{3} \mathrm{~L}^{-3}\right)$. From Eq. (5), it follows that

$$
\psi(\theta)=-\ln \left[\left(\theta-\theta_{r}\right) /\left(\theta_{s}-\theta_{r}\right)\right] / \delta
$$

For a one-dimensional flow in a semi-finite column of homogeneous soil, the moisture content within the column is (Cavalcante and Zornberg 2017 [6]):

$$
\theta(z, t)=\theta_{i}+\left(\theta_{0}-\theta_{i}\right) B(z, t)
$$

where $z=$ distance from the column top (L); $t=$ time after the imposed boundary conditions (T); $\theta_{i}=\theta(z, 0)$ is the initial condition: a uniform moisture content within the column; $\theta_{0}=\theta(0, t)$ is the upper boundary condition: constant moisture at the column top. A lower boundary condition is also needed: $\partial \theta(W T, t) / \partial z=0$, where $z=W T$ is the depth of the water table. The auxiliary function $B(z, t)$ is given approximately by (Cavalcante and
Zornberg 2017 [6]):

$$
\begin{aligned}
& B(z, t)=\frac{1}{2} \operatorname{erfc}\left(\frac{z-a_{s} t}{2 \sqrt{D_{z} t}}\right)+\frac{1}{2} \exp \left(\frac{a_{s} z}{D_{z}}\right) \operatorname{erfc}\left(\frac{z+a_{s} t}{2 \sqrt{D_{z} t}}\right) \\
& +\left(1+\frac{a_{s}(2 W T-z)+a_{s}^{2} t}{2 D_{z}}\right) \operatorname{erfc}\left(\frac{2 W T-z+a_{s} t}{2 \sqrt{D_{z} t}}\right) \times \\
& \exp \left(\frac{a_{s} W T}{D_{z}}\right)-\sqrt{\frac{a_{s}^{2} t}{\pi D_{z}}} \exp \left[\frac{a_{s} W T}{D_{z}}-\frac{\left(2 W T-z+a_{s} t\right)^{2}}{4 D_{z} t}\right]
\end{aligned}
$$

where $D_{z}=k_{s} /\left(\delta\left(\theta_{s}-\theta_{r}\right) \gamma_{w}\right)$ is the constant unsaturated water diffusivity $\left(\mathrm{L}^{2} \mathrm{~T}^{-1}\right) ; a_{s}=k_{s} /\left(\theta_{s}-\theta_{r}\right)$ is the constant unsaturated advective seepage $\left(\mathrm{LT}^{-1}\right)$, and $k_{s}=$ saturated hydraulic conductivity of the soil $\left(\mathrm{LT}^{-1}\right)$.

\section{Unsaturated pile shaft resistance model}

The water flow occurs on the unsaturated zone only $(0 \leq z \leq W T)$, so Eq. (7) becomes:

$$
\theta(z, t)= \begin{cases}\theta_{i}+\left(\theta_{0}-\theta_{i}\right) B(z, t), & \text { if } z \leq W T \\ \theta_{s}, & \text { otherwise }\end{cases}
$$

Zhai et al. (2019) [8] adopted a suction value of $3100 \mathrm{kPa}$ corresponding to the residual degree of saturation. Beyond this value, it was suggested by Plaster (2009) [9] that only hygroscopic water remains on soil, which cannot transfer stress between soil particles. From Eq. (5) and using $S=\theta / \theta_{s}$, the residual degree of saturation is obtained as

$$
S^{\prime}=\left[\left(\theta_{s}-\theta_{r}\right) \exp (-3100 \delta)+\theta_{r}\right] / \theta_{s}
$$

and the transient effective degree of saturation is:

$$
S_{e}(z, t)=\left(S(z, t)-S^{\prime}\right) /\left(1-S^{\prime}\right)
$$

We defined the soil matric suction as $\psi=-u_{w}$, neglecting the pore-air pressure and the osmotic suction (total suction equals the sum of the matric and osmotic suction). Below the water table, we have the hydrostatic condition $u_{w}=\gamma_{w}(z-W T)$. Using Eqs. (6) and (9) the matric suction is defined as:

$$
\psi(z, t)= \begin{cases}-\frac{1}{\delta} \ln \left(\frac{\theta(z, t)-\theta_{r}}{\theta_{s}-\theta_{r}}\right), & \text { if } z \leq W T \\ -\gamma_{w}(z-W T), & \text { otherwise }\end{cases}
$$

It was assumed a linear transition with the saturation between the dry and the saturated unit weight; the following relation was adopted for the soil unit weight:

$$
\gamma(z, t)=\gamma_{d}+\left(\gamma_{s a t}-\gamma_{d}\right) S(z, t)
$$

where $\gamma_{d}=$ dry unit weight $\left(\mathrm{ML}^{-2} \mathrm{~T}^{-2}\right)$. The total vertical stress can be defined as the integration of Eq. (13) ( $z^{\prime}$ is a dummy variable): 


$$
\sigma_{v}(z, t)=\int_{0}^{z} \gamma\left(z^{\prime}, t\right) \cdot d z^{\prime}
$$

Substituting Eqs. (11), (12) and (14) into Eq. (3), it was defined as the transient unsaturated shear strength:

$$
\tau(z, t)=c^{\prime}+\beta \sigma_{v}(z, t)+\tau_{u}(z, t)
$$

where $\tau_{u}=\beta S_{e}(z, t) \psi(z, t)=$ unsaturated part of the shear strength, and the second term is the total horizontal stress. Thus, the transient shaft resistance is

$$
Q_{f}(L, t)=\left(\int_{0}^{L} \tau(z, t) d z\right) P
$$

The transient analysis works only for a homogeneous soil layer in $z<W T$. For a predetermined moisture profile, it is only needed to define $\theta(z)$ and the other parameters varying with depth. In this study, the analysis is focused on transient behavior during a water flow downwards.

In the engineering design, the factor of safety $(F S)$ is indispensable to enclose the uncertainty of the structure parameters; in this case, it reduces the calculated soil resistance. The factor of safety variation with time was analyzed with the following relation:

$$
F S^{*}(L, t)=F S \cdot Q_{f}(L, t) / Q_{f}(L, 0)
$$

where $F S^{*}$ is the real factor of safety after a time $t$ of water infiltration for a pile length of $L$, and $F S$ is a constant factor of safety applied for the initial condition $(t=0)$. Fig. 1 summarizes the methodology of the paper.

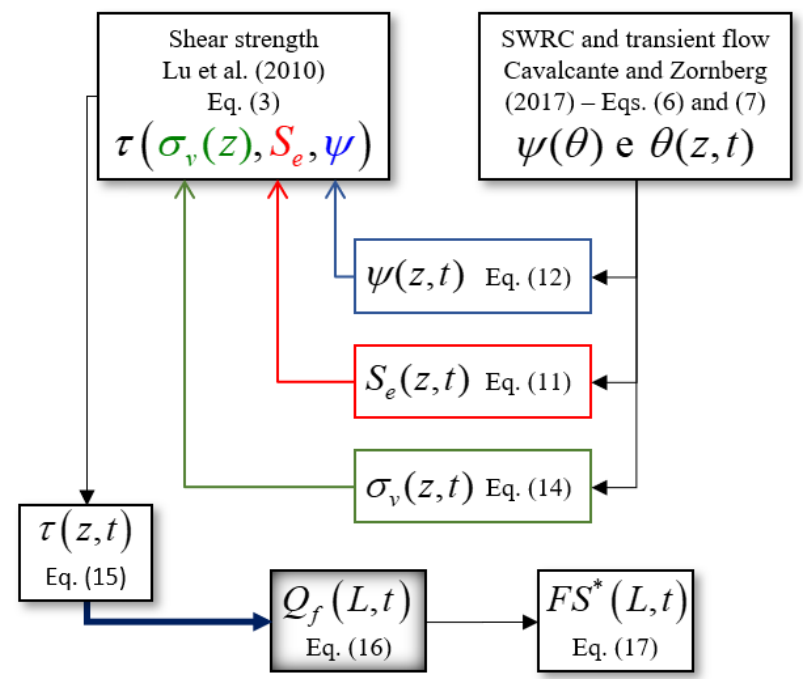

Fig. 1. Flowchart of the analytical model for transient unsaturated pile shaft resistance.

\section{Results and discussion}

Parametric evaluations were conducted on the shear strength parameters and shaft resistance developed in this study during a water infiltration event. The model's accuracy relies upon the correct estimation of surrounding soil parameters $\left(\delta, \theta_{s}, \theta_{r}, K, c^{\prime}, \phi^{\prime}, k_{s}\right.$, and $\left.\gamma_{d}\right)$ after the pile construction. The soil structure is disturbed in this process, and the soil parameters may not be the same as before it. Thus, for the pile design, modification in these parameters in accordance with the pile placement method for computing the shaft resistance is essential but is not analyzed in this study.

The unsaturated part of the shear strength, disregarding $\beta$ (i.e., on a horizontal surface), can be rearranged as a function of soil suction $-\psi S_{e}(\psi)$. The unsaturated shear strength does not contribute when the soil suction is null or when the degree of saturation is close to or equals zero (high suction values; the residual zone). This behavior is observed in Fig. 2, considering $S_{e}=0$ when $S_{e}<S^{\prime}$.

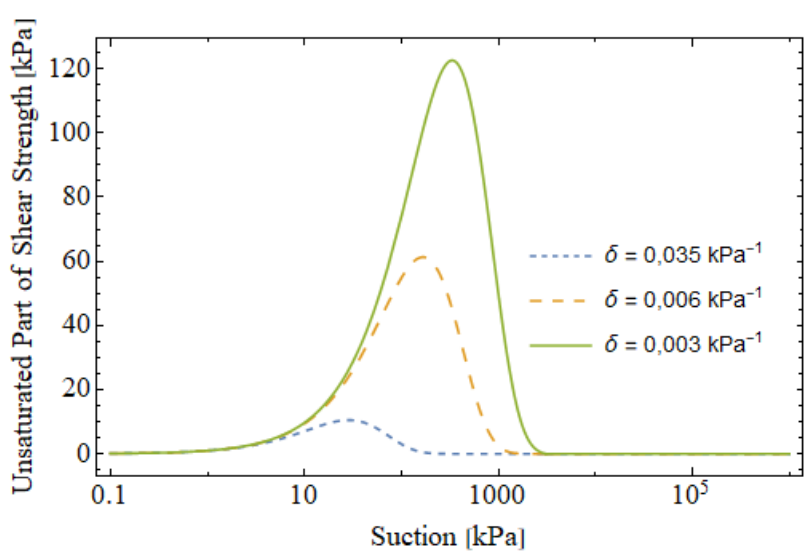

Fig. 2. Unsaturated part of the horizontal shear strength (disregarding $\beta$ ) varying with soil matric suction $\left(\theta_{s}=0.40\right.$; $\left.\theta_{r}=0.01\right)$.

The greater the $\delta$ value is, the more coarse-grained is the soil because the volumetric water content decreases faster at increasing suction. As shown in Fig. 2, the more fine-grained the soil, the higher suction is needed to reach a significant contribution towards shear strength, but this contribution can be greater than for coarse-grained soil. The hysteresis of the SWRC and the collapsible behavior of some soils upon wetting and drying process are not considered here due to its complex modeling.

During an infiltration process, the water content in a specific depth varies with time. Fig. 3(a) shows some moisture profiles calculated using Eq. (9) at different times after the beginning of the infiltration process in a soil layer with the following constant parameters: $\theta_{s}=0.40 ; \theta_{r}=0.01 ; \theta_{0}=0.39$ (maximum); $\theta_{i}=0.39$; $\delta=0.004 \mathrm{kPa}^{-1} ; \quad k_{s}=3 \cdot 10^{-6} \mathrm{~m} / \mathrm{s} \quad$ (typical clayey soil); $W T=15.0 \mathrm{~m} ; \gamma_{w}=9.81 \mathrm{kN} / \mathrm{m}^{3}$. The maximum value of the upper boundary condition is $\theta_{0}=\theta_{s}-\theta_{r}$ to limit the infiltration rate below the $k_{s}$ value (Cavalcante and Zornberg 2017 [6]).

It is observed a discontinuity at the water table $(z=15 \mathrm{~m})$ due to the simplified definition of the model: an initial moisture content (and suction) constant with depth and a disregard of the capillary ascension from the saturated zone. If these two considerations and the soil homogeneity in the unsaturated zone are reasonable, the model can be accurate.

In Fig. 3(b) it is observed the change in soil suction or the negative of the pore-water pressure for $z>W T-$ during the water flow (Eq. (12)). Because it was not 
adopted a smooth transition at the water table in the moisture content, there is also a discontinuity in the suction profile at this depth. Above the water table, the suction values decrease with time for specific depth, as the moisture content increases. The suction value below the water table assumes a hydrostatic pressure, which decreases linearly with depth and does not depend on time.

As defined by Eq. (13), the soil unit weight has the same behavior as the moisture content during the infiltration event since it is a linear combination of $\theta(z, t)$ and a constant value. For a specific depth, the total vertical stress (Fig. 4(a), considering $\gamma_{d}=15.9 \mathrm{kN} / \mathrm{m}^{3}$ ) small changes is due to the relatively small changes in the unit weight (less than $10 \%$ in this case) since it varies from the initial value of $17.76 \mathrm{kN} / \mathrm{m}^{3}$ to near of the saturated unit weight $\left(19.53 \mathrm{kN} / \mathrm{m}^{3}\right)$ at most. As a result of the increased moisture content with time for a constant depth (similarly for the unit weight), the total vertical stress increases at a specific depth during the water flow process. Since it is defined by an integral along with the depth, there is no discontinuity at the water table. The total vertical stress below the water table varies linearly with depth due to the constant saturated unit weight in this zone.

The unsaturated part of the shear strength $\left(\beta S_{e}(z, t)\right.$ $\psi(z, t))$ has a similar behavior of the soil suction on the unsaturated zone, including the discontinuity at the water table, which can be observed in Fig. 4(b), with $K=0.6$ and $\phi^{\prime}=22^{\circ}$. Below the water table, this variable assumes the hydrostatic condition form in the classical effective stress.
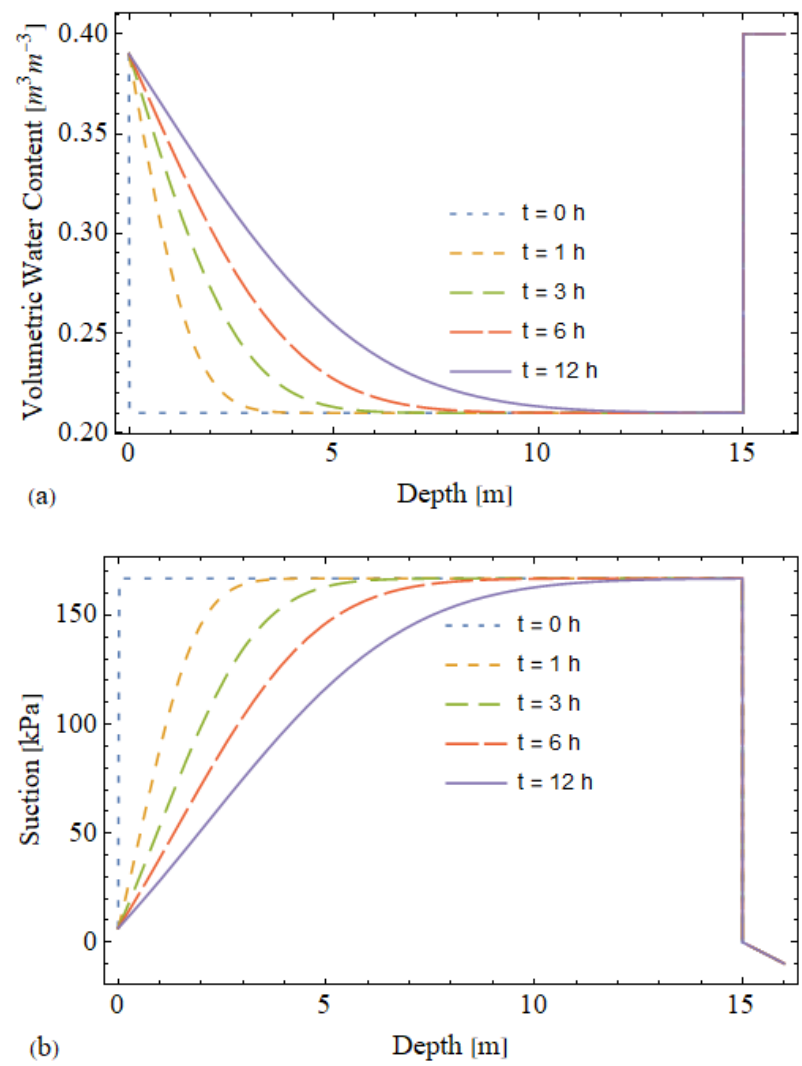

Fig. 3. Profile during water infiltration at increasing time of (a) volumetric water content and (b) soil suction $\left(\delta=0.004 \mathrm{kPa}^{-1}\right.$, $k_{s}=3 \cdot 10^{-6} \mathrm{~m} / \mathrm{s}, \theta_{0}=0.39$, and $\theta_{i}=0.21$ - fine-grained soil).
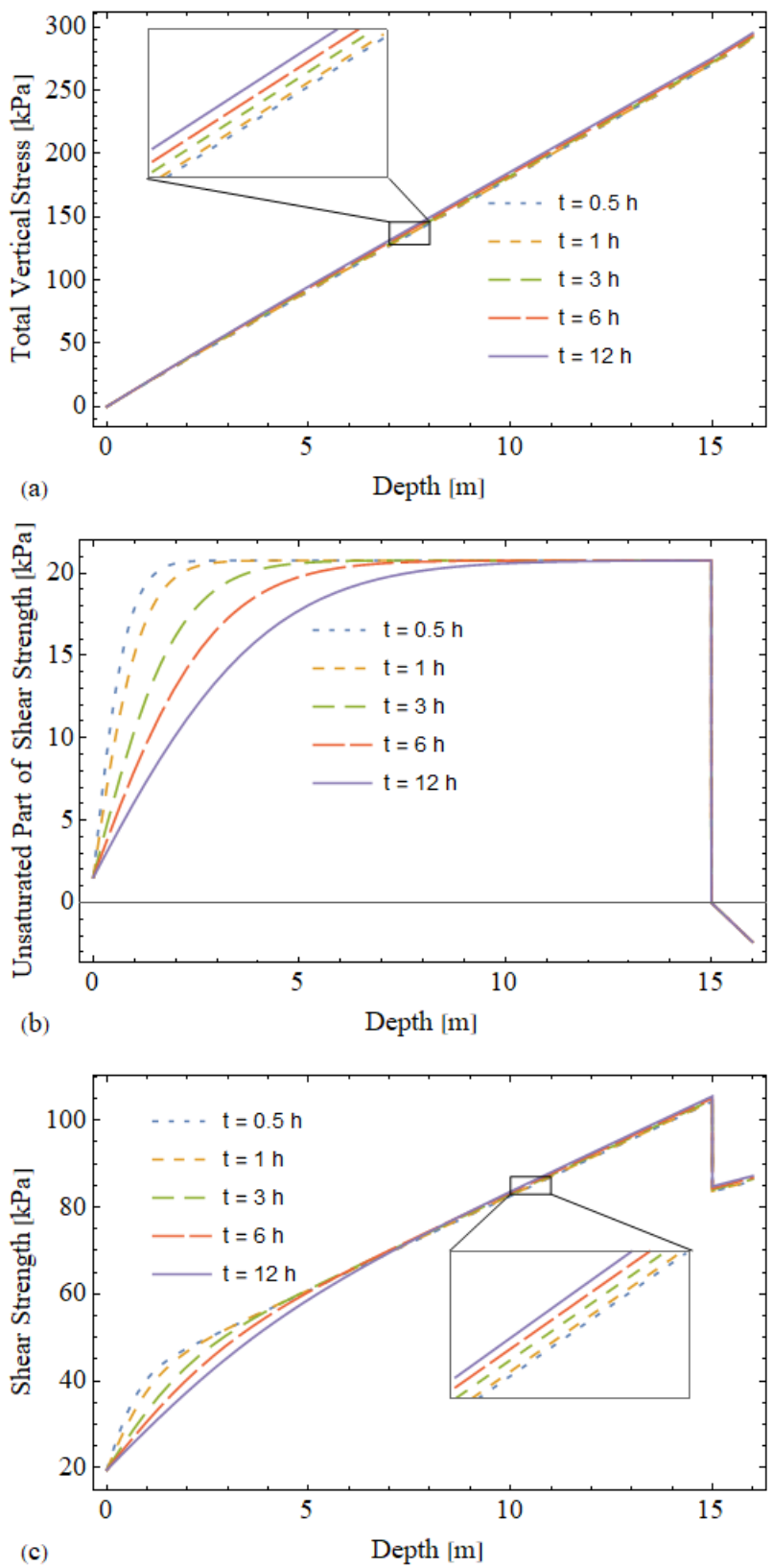

Fig. 4. (a) Total vertical stress, (b) unsaturated part of the shear strength on the pile surface, and (c) soil shear strength on pile surface at increasing depth $\left(\delta=0.004 \mathrm{kPa}^{-1}, \gamma_{d}=15.9 \mathrm{kN} / \mathrm{m}^{3}\right.$, $K=0.6, c^{\prime}=18 \mathrm{kPa}$, and $\phi^{\prime}=22^{\circ}-$ fine-grained soil $)$.

Fig. 4(c) is presented the shear strength function (Eq. (15)), considering $c^{\prime}=18 \mathrm{kPa}$. In this case, it is observed a zone where the shear strength decreases at a specific depth with increasing time (about $z<8 \mathrm{~m}$ ), and another zone where the shear strength is slightly greater for higher time values (about $8 \mathrm{~m}<z<15 \mathrm{~m}$ ). In the first one, the decreasing of the unsaturated part of the shear strength with time is more significant than the increase of the total horizontal stress $\left(\beta \sigma_{v}(z, t)\right)$ with time. In the second zone, there is small or no change of the unsaturated part of the shear strength with time because the suction remains nearly constant; the increasing of the total horizontal stress in this zone becomes more significant.

In the saturated zone, the unsaturated part of the shear strength is constant for a fixed depth, and the total vertical stress is always increasing with time; accordingly, the 
shear strength increases during the water flow in this zone, similar to the second zone (about $8 \mathrm{~m}<z<15 \mathrm{~m}$ ). The shear strength increases linearly at increasing depth for a fixed time since the saturated effective stress $\left(\sigma_{v}-\gamma_{w}(z-W T)\right)$ varies linearly with depth. The discontinuity at the water table is due to the discontinuous suction, reflecting on the unsaturated part of the shear strength only (since $c$ ' and $\sigma_{v}$ are continuous).

The pile shaft resistance $\left(Q_{f}\right)$ varying during the infiltration process is presented in Fig. 5(a), for a pile section diameter of $0.30 \mathrm{~m}$ (perimeter of $P=0.94 \mathrm{~m}$ ). The $Q_{f}$ increases with the pile length, as expected from the problem physics, and the definition as an integral of a positive function. In this case, for a fine-grained soil, the $Q_{f}$ decreases with time for specific depth, since the cumulative contribution of the shear strength with time is observed to be decrescent in Fig. 4(c) (the cumulative variation on the unsaturated part of the shear strength is more significant than the cumulative variation on the cohesion plus the total horizontal stress). Fig. 5(a) also shows the saturated shaft resistance, considering the water table at the ground surface ( $W T=0 \mathrm{~m}$, Eq. (4)).

Fig. 5(b) shows the variation of the factor of safety (Eq. (17), for $F S=1.4$ ): the shorter the pile, the greater its shaft resistance decrease during water infiltration. It shows the importance of designing the shaft resistance considering moisture condition variation besides the initial. The $F S=1.4$ was adopted to illustrate only but could be reasonable assuming a rigorous subsoil investigation (ABNT 2019 [10]) from both saturated and unsaturated soil parameters.

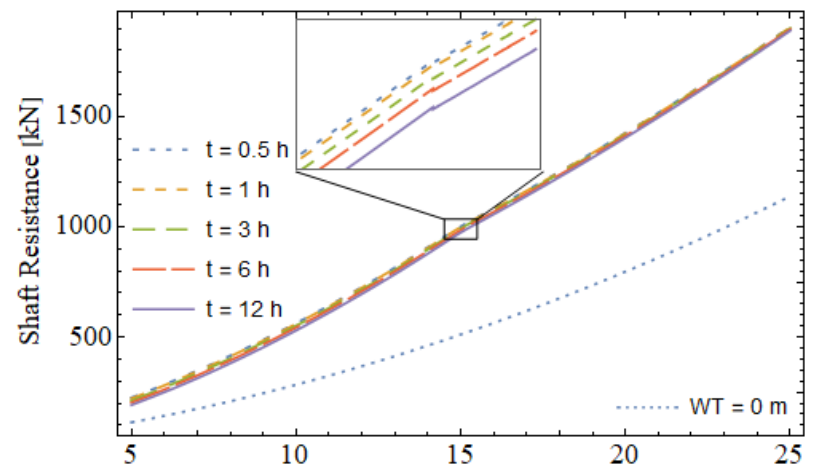

(a)

Pile Length $[\mathrm{m}]$

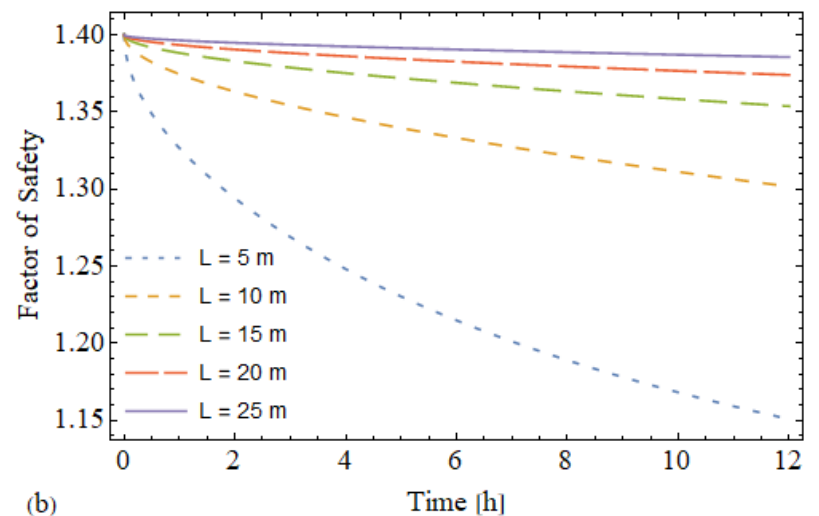

Fig. 5. (a) shaft resistance of a pile at increasing depth and (b) its factor of safety at increasing time in a drained loading condition ( $\delta=0.004 \mathrm{kPa}^{-1}$ - fine-grained soil).

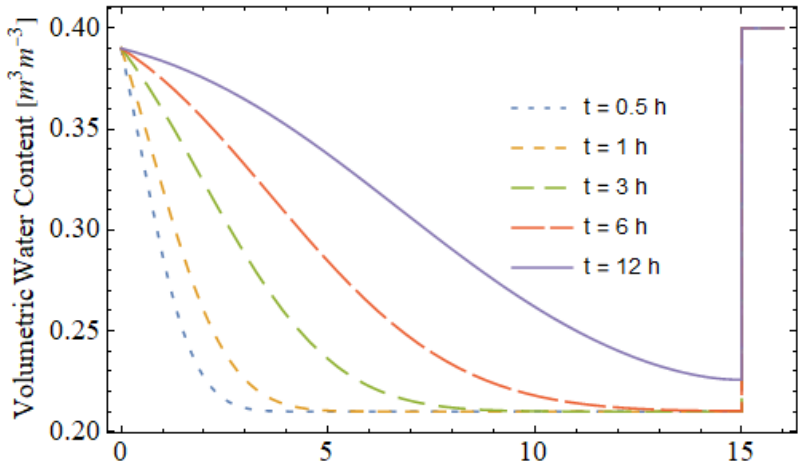

(a) Depth $[\mathrm{m}]$

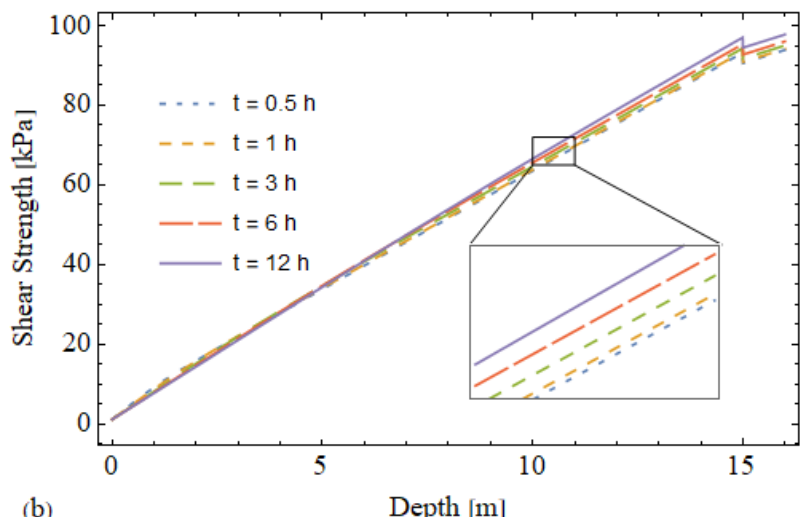

Fig. 6. Profiles during water infiltration at increasing depth of (a) volumetric water content and (b) soil shear strength on pile surface $\left(\delta=0.04 \mathrm{kPa}^{-1}, \quad k_{s}=5 \cdot 10^{-5} \mathrm{~m} / \mathrm{s}, \quad \theta_{0}=0.39, \quad \theta_{i}=0.21\right.$, $\gamma_{d}=15.9 \mathrm{kN} / \mathrm{m}^{3}, K=0.55, c^{\prime}=1 \mathrm{kPa}$, and $\phi^{\prime}=31^{\circ}-$ coarsegrained soil).

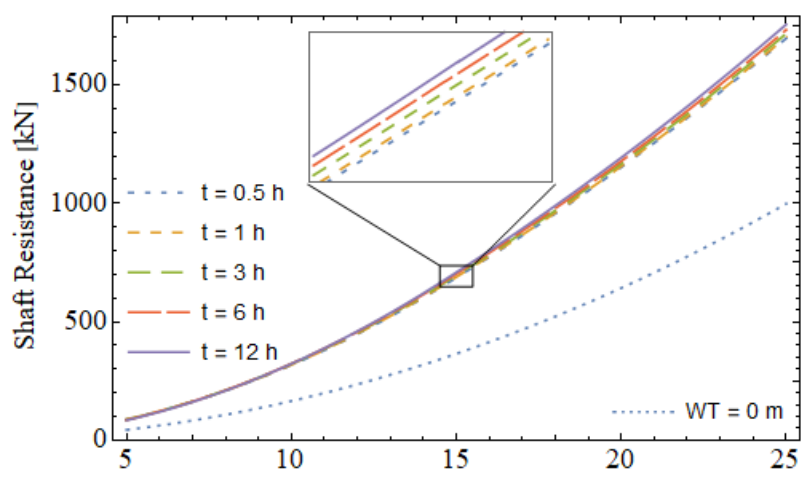

(a)

Pile Length $[\mathrm{m}]$

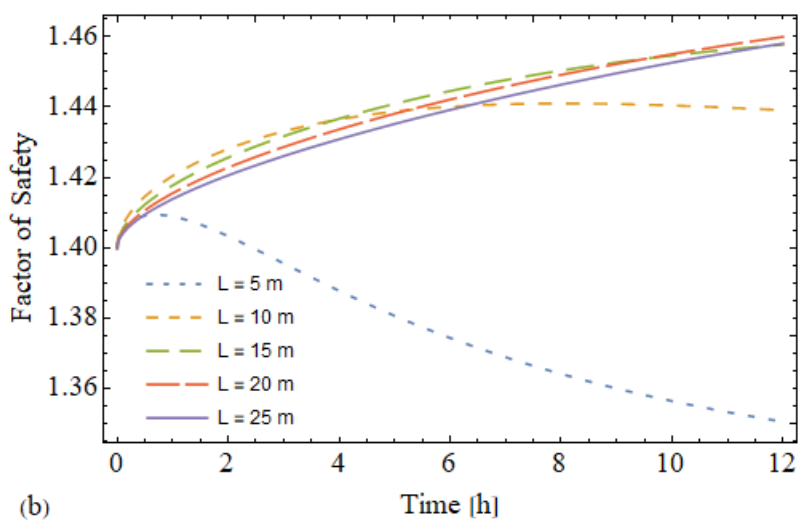

Fig. 7. (a) shaft resistance of a pile at increasing depth and (b) its factor of safety at increasing time in a drained loading condition ( $\delta=0.04 \mathrm{kPa}^{-1}-$ coarse-grained soil). 
For a coarse-grained soil $\left(\delta=0.04 \mathrm{kPa}^{-1}\right.$, $k_{s}=5 \cdot 10^{-5} \mathrm{~m} / \mathrm{s}, \quad c^{\prime}=1 \mathrm{kPa}, \quad \phi^{\prime}=31^{\circ}, \quad$ and $K=0.55$; maintaining the other parameters $-\theta_{s}, \theta_{r}, \theta_{0}, \theta_{i}$, and $\gamma_{d}-$ to illustrate), it is observed a greater moisture content for a fixed time and depth when compared to a fine-grained soil (Fig. 2 (a)), as shown in Fig. 6(a). In Fig. 6(b), it is clear that the discontinuity of the shear strength at the water table is much smaller than in Fig. 4(c), which means that the unsaturated part of the shear strength contribution is smaller than in clayey soil. As for clayey soil, it is also observed in Fig. 6(b) the first zone for smaller depth values where the unsaturated part of shear strength is predominant, leading to a decreasing over time, and a second zone closer to the water table where the opposite occurs due to the still unchanged soil suction.

The shaft resistance for the sandy soil tends to increase with time for larger piles (the cumulative decreasing of the unsaturated part of the shear strength is less significant than the cumulative increase of the cohesion plus the total vertical stress), as observed in Fig. 7. The saturated shaft resistance $(W T=0 \mathrm{~m})$ remains smaller than the unsaturated one because, in the first case, the suction becomes negative (increasing positive pore-water pressure with increasing depth). In contrast, in the second case, the unsaturated shear strength is small $(<5 \mathrm{kPa}$ in this case) but still positive.

The factor of safety (Fig. 7(b), using $F S=1.4$ ) is greater for a given pile length than a fine-grained soil (Fig. 5(b)), assuming even values greater than 1.4, which represents an increase in shaft resistance with time.

For both general cases of typical fine-grained or coarse-grained soil, it was observed (Fig. 5(a) and Fig. 7(a)), a very significant decrease in pile resistance when considering the saturated approach. It demonstrates the potential of a more economical design of pile foundation based on an unsaturated approach for regions where there is always an expressive part of the upper soil layer in the unsaturated state.

\section{Summary and conclusions}

This study developed an analytical transient unsaturated shear strength equation, coupling the unsaturated shear strength equation and the transient analytical solution for the water flow of Cavalcante and Zornberg (2017). In particular, it was adopted a constant residual suction value to nullify the contribution of suction on the shear strength in the residual zone. Furthermore, it was modeled a transient shaft resistance for a single pile considering a drainage condition: applying the $\beta$ coefficient from Burland (1973) in the vertical effective stress ( $\mathrm{Lu}$ and Likos 2004) and integrating the transient unsaturated shear strength for obtaining the shaft resistance as a function of the pile length and the time. The $\beta$ coefficient might also be adjusted for each field soil condition, pile type, and pile-placement method.

The unsaturated contribution towards the shear strength tends to be more critical for fine-grained soils because it is greater than coarse-grained soils; this unsaturated part decreases with increasing soil moisture.
The transient solution proposed for the shaft resistance is limited for a homogeneous soil layer above the water table (for the water flow model to be valid). Conversely, if there is a predefined moisture profile, the solution is applicable for multiple soil layers. It is just required to define the parameters as a function of depth.

The analysis conducted in this study demonstrates the potential of the proposed model of unsaturated pile ultimate resistance to assist in the design of pile foundation - besides other unsaturated shear strength applications -, which may be suitable for more economic pile designs in arid or semi-arid regions where there is always an expressive length of the unsaturated zone above the water table.

Some aspects can be considered for the advancing of the proposed modeling for the pile design: implement a model of the water flow through multiple layers; implement a hydrology analysis to predict the moisture condition and position of the water table that will result in the smallest resistance during the lifespan of the pile structure for the unsaturated design; model the undrained resistance of a pile; validate the transient unsaturated shear strength model and its applicability for pile resistance experimentally.

\section{Acknowledgments}

This study was financed in part by the Coordination for the Improvement of Higher Education Personnel Brazil (CAPES) - Finance Code 001. The authors also acknowledge the support of the National Council for Scientific and Technological Development (CNPq Grant 435962/2018-3, 137828/2019-5, 305484/2020-6), the Foundation for Research Support of the Federal District (FAPDF) (Projects 0193.002014/2017-68 and $0193.001563 / 2017)$, and the University of Brasília.

\section{References}

1. N. Lu \& W. J. Likos. (2004). Unsaturated soil mechanics. Hoboken, NJ: Wiley.

2. D. G. Fredlund, H. Rahardjo, M. D. Fredlund. (2012). Unsaturated soil mechanics in engineering practice. Hoboken, NJ: Wiley.

3. A. W. Bishop (1959). The principle of effective stress. Teknisk Ukeblad, 106(39), 859-863.

4. N. Lu, J. W. Godt, D. T. Wu (2010). A closed-form equation for effective stress in unsaturated soil. Water Resour. Res., 46, W05515. DOI: 10.1029/2009WR008646.

5. S. K. Vanapalli, Taylan, Z. N. (2012). Design of single piles using the mechanics of unsaturated soils. Int. J. GEOMATE, 2(1), 197-204.

6. A. L. B. Cavalcante \& J. G. Zornberg (2017). Efficient approach to solving transient unsaturated flow problems. I: Analytical solutions. Int. J. Geomech. 17 (7): 4017013. DOI: 10.1061/(ASCE)GM.1943-5622.0000875. 
7. J. B. Burland (1973). Shaft friction of piles in clay a simple fundamental approach. Ground Engineering 6-3, 30-42.

8. Q. Zhai, H. Rahardjo, A. Satyanaga, et al (2019). Estimation of unsaturated shear strength from soilwater characteristic curve. Acta Geotechnica 14, 1977-1990. DOI: 10.1007/s11440-019-00785-y.

9. E. J. Plaster (2009). Soil science and management. Delmar, Clifton Park.

10. Brazilian Association of Technical Standands (2019). ABNT NBR 6122: design and construction of foundations. Rio de Janeiro, RJ. 